\title{
PERBAIKAN KONTRAS CITRA MENGGUNAKAN TEKNIK BRIGHTNESS ADJUSTMENT UNTUK SISTEM EKSTRAKSI GARIS PANTAI
}

\author{
I Made Rai Putera Yasa ${ }^{1}$, I Made Oka Widyantara ${ }^{2}$, NMAE Dewi Wirastuti ${ }^{3}$ \\ ${ }_{1,2,3}$ Lab. Sistem Telekomunikasi, Program Studi Teknik Elektro \\ Fakultas Teknik, Universitas Udayana \\ Badung, Indonesia \\ Email : raiputerayasa@gmail.com ${ }^{1}, \underline{\text { oka.widyantara@unud.ac.id }}{ }^{2}, \underline{\text { dewi.wirastuti@unud.ac.id }}{ }^{3}$
}

\begin{abstract}
Abstrak
Studi ini telah melakukan evaluasi penerapan teknik brightness adjustment untuk memperbaiki kekontrasan citra dalam rangka ekstraksi garis pantai pada sistem monitoring deteksi garis pantai berbasis video. Pada sistem monitoring ini, mekanisme deteksi garis pantai dilakukan dengan pengenalan objek daratan dan laut pada citra video. Perubahan kondisi laut akibat perubahan cuaca menyebabkan terjadinya perubahan tingkat kekontrasan pada citra video pantai. Perubahan kekontrasan akan menyebabkan deteksi garis pantai menjadi tidak akurat. Teknik brightness adjustment diterapkan pada proses pra-pengolahan citra untuk menghasilkan tingkat kekontrasan citra yang stabil pada segala kondisi sehingga sistem monitoring pantai dapat mengekstraksi garis pantai secara akurat. Teknik brightness adjustment dapat menyesuaikan kecerahan citra pantai dengan mengatur nilai ambang batas atas dan bawah setiap intensitas piksel. Penelitian ini menggunakan 3 (tiga) sampel citra video uji yang diambil pada kondisi pagi, siang dan sore hari untuk mendapatkan karakteristik citra video yang berbeda. Hasil simulasi menunjukkan bahwa penerapan teknik brightness adjustment mampu meningkatkan akurasi ekstraksi garis pantai ketika menggunakan nilai ambang batas masing-masing pada nilai -20\% untuk kondisi citra pagi, -40\% untuk kondisi citra siang hari, dan -35\% untuk kondisi citra sore hari.
\end{abstract}

Kata kunci : Brightness Adjustment, Ekstraksi Garis Pantai, Sistem Monitoring Pantai.

\begin{abstract}
This study has evaluated the application of brightness adjustment technique to improve image contrast in the framework of coastline extraction on video-based shoreline monitoring system. In this monitoring system, the shoreline detection mechanism is done by introducing the land and sea objects in the video image. Changes in sea conditions due to weather changes cause a change in the contrast in the coastal image. The change in contrast will lead to inaccurate coastline detection. The brightness adjustment technique is applied to the image pre-processing to produce stable contrast in all conditions so that the coastal monitoring system can extract the coastline accurately. The brightness adjustment technique can adjust the brightness of the coastal image by setting the upper and lower threshold values of each pixel intensity. This study used 3 (three) sample video test images taken on morning, noon and afternoon to obtain different video image characteristics. The simulation results show that the application of brightness adjustment technique can increase the accuracy of shoreline extraction when using the threshold value of each at $-20 \%$ for morning image condition, $-40 \%$ for daytime image condition, and $-35 \%$ for afternoon image condition .
\end{abstract}

Keywords: Brightness Adjustment, Coastline Extraction, Beach Monitoring System. 


\section{Pendahuluan}

Deteksi garis pantai dilakukan untuk mengetahui posisi garis pantai akibat pengikisan terus menerus oleh air laut. Dengan mengetahui posisi garis pantai, pihak-pihak terkait dapat melakukan tindakan pencegahan maupun penyelamatan lingkungan pantai. Morfologi pantai berubah dalam skala spasial dan temporal yang berbeda. Maka dari itu diperlukan skema monitoring yang intensif [1]. Deteksi garipantai dengan menggunakan kamera monitoring merupakan salah satu cara pemantauan/monitoring yang murah dan dapat dilakukan dari jarak jauh (remote sensing).

Hasil monitoring berupa video pantai, kemudian diambil frame-frame dalam rentang waktu tertentu akan menghasilkan citra daerah pesisir. Citra pantai adalah citra berwarna yang memiliki komposisi iluminasi berdasarkan waktu pengambilan citra. Pengaruh dari iluminasi cahaya matahari pada citra pantai memberikan permasalahan ketika memisahkan objek pada proses segmentasi [2]. Oleh karena itu diperlukan brightness adjustment pada frame citra monitoring video pantai sebelum dilakukan analisis lebih lanjut.

Teknik brightness adjustment untuk pengenalan objek secara otomatis telah diteliti sebelumnya oleh [3] dengan memanfaatkan ruang warna $C I E$ L*a*b* dan sistem fuzzy. Metode yang diusulkan menyesuaikan kecerahan citra yang diberikan dengan memperhatikan komponen RGB dan komponen $\mathrm{L}$ pada ruang warna CIE $\mathrm{L}^{*} \mathrm{a}^{*} \mathrm{~b}^{*}$. Selanjutnya, metode yang diusulkan menerapkan sistem pengambilan keputusan fuzzy untuk menentukan koefisien penyesuaian setiap piksel untuk menyesuaikan kecerahan citra. Dari hasil penelitian tersebut diketahui bahwa metode yang diusulkan dapat menyesuaikan citra yang diberikan secara efisien dan otomatis.

Pada kerangka kerja sistem ekstraksi dan deteksi garis pantai berbasis kamera video, teknik contrast stretching telah diterapkan untuk memperbaharui kekontrasan citra pantai yang diusulkan oleh [4]. Dalam kerangka kerja deteksi garis pantai secara otomatis, citra pantai yang telah diperbaharui tingkat kecerahannya, selanjutnya disegmentasi untuk memilah obyekobyek dalam citra pantai. Mekanisme pemilahan menggunakan teknik Self Organizing Map (SOM). Selanjutnya, hasil segmentasi obyek- obyek dalam citra pantai diklasifikasi menjadi 3 (tiga) area yaitu area daratan, laut dan langit, menggunakan teknik K-Nearest Neighbor (K$\mathrm{NN}$ ). Identifikasi nilai piksel-piksel pada area daratan terhadap piksel-piksel area laut, selanjutnya digunakan sebagai dasar untuk mengekstraksi dan deteksi garis pantai. Hasil penelitian ini telah menunjukkan bahwa penerapan teknik contrast stretching untuk memperbaharui kekontrasan citra pantai dapat mendukung proses ekstraksi garis pantai. Akan tetapi, pengujian kinerja belum dilakukan pada sampel citra yang diakuisisi pada kondisi yang berbeda-beda.

Sebagai upaya untuk mendapatkan sebuah mekanisme pengaturan kecerahan pada citra pantai untuk sistem deteksi garis pantai berbasis kamera video, penelitian ini mengusulkan penerapan teknik brightness adjustment. Brightness adjustment merupakan salah satu teknik pra-pengolahan citra berbasis operasi titik yang digunakan untuk meningkatan kualitas kecerahan citra pada setiap titik piksel. Brightness adjustment berguna ketika citra yang hendak diproses memiliki tingkat kecerahan yang kurang atau lebih akibat iluminasi / pencahayaan sehingga objek pada citra sulit untuk dibedakan satu dengan yang lainnya

Paper ini disusun sebagai berikut. Pada bagian 1, dijelaskan latar belakang pemilihan teknik brightness adjustment untuk deteksi garis pantai. Bagian 2 data dan metode yang diusulkan dalam penelitian, bagian 3 menjelaskan hasil penelitian dan pembahasannya. Terakhir, bagian 4 adalah kesimpulan dari penelitian.

\section{DATA DAN METODE}

A. Data

Di antara banyak fitur yang ada di lingkungan dekat pantai, garis pantai adalah salah satu yang paling jelas karena dapat didefinisikan oleh kontak antara pasir pantai dan air. Meski merupakan fitur yang mudah dikenali di lapangan, penentuan gambar digitalnya adalah tidak mudah dibedakan karena gradien di pasir basah. Dengan demikian, pendeteksian tepi merupakan cara termudah untuk mempelajari hubungan dinamis antara darat dan laut.

Pada sistem video untuk monitoring pantai, terdapat beberapa tipe citra pantai yang dapat diekploitasi untuk mendapatkan deteksi garis 
pantai, yaitu: 1) Snap adalah representasi frame tunggal dari video, dan 2) Timex (Time Exposure) menyatakan rata-rata dari 600 frame video yang dihimpun dalam interval 10 menit. Tipe citra Timex adalah yang sering digunakan dalam area penelitian deteksi garis pantai, karena tingkat perubahan kekontrasan citra yang homogen.

Penelitian ini menggunakan sampel citra tipe Timex yang diambil dari dataset video monitoring pantai Egmond Aan Zee, Belanda yang diunduh dari situs http://arguspublic. deltares.nel/archive/?site=porthtow.

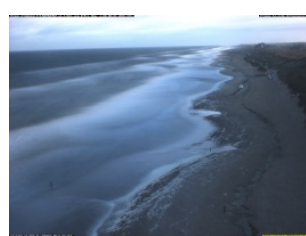

a

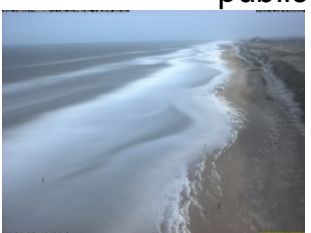

b

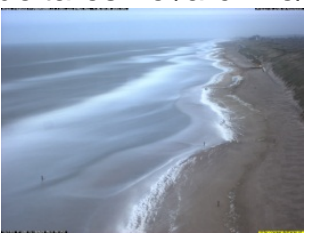

C

Gambar 1. Sampel citra Timex, a. Citra pagi, b. Citra siang, c. Citra sore

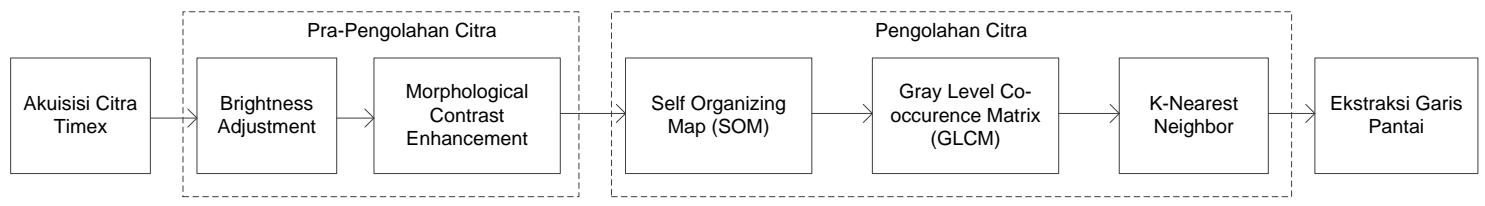

Gambar 2. Kerangka kerja sistem deteksi garis pantai yang diusulkan

Seperti ditunjukkan pada Gambar 1, sampel citra yang digunakan adalah citra timex yang diakuisisi pada pagi, siang dan sore hari, untuk menunjukkan perbedaan tingkat iluminasi dari cahaya matahari.

\section{B. Metode yang Diusulkan}

Seperti ditunjukan pada Gambar 2, paper ini berkontribusi pada penerapan teknik brightness adjustment pada tahap prapengolahan citra di kerja sistem deteksi garis pantai [4].

\section{1) Pra-Pengolahan Citra Berbasis Brightness Adjustment}

Brightness adjustment merupakan operasi pixel yang paling sederhana. Penyesuaian tingkat kecerahan suatu citra dapat dinyatakan sebagai:

$$
U^{\prime}=U+C
$$

dengan $U^{\prime}$ dan $U$ berturut-turut menyatakan citra setelah dan sebelum brightness adjustment sedangkan $c$ adalah suatu konstanta yang merupakan variabel penyesuaian.

Proses brightness adjustment dilakukan dengan menambahkan atau mengurangkan nilai setiap pixel dengan suatu konstanta. Apabila nilai pixel setelah penyesuaian melebihi nilai maksimum intensitas yang mungkin untuk citra grayscale. Nilai maksimum intensitas adalah 255, maka nilai pixel tersebut akan dijadikan 255. Demikian pula sebaliknya, bila nilai pixel hasil penyesuaian lebih kecil dari nol maka nilai pixel tersebut dijadikan nol [5].

Penelitian dilakukan dengan menerapkan teknik brightness adjustment pada aplikasi variabel monitoring video pantai. Adapun sintak MATLAB untuk metode brightness adjustment adalah sebagai berikut: $x=\underset{\text { imadjust(imgarr,[low_in high_in],[low_out }}{\text { high_out]) }}$

Pada fungsi imadjust terdapat tiga buah variabel yang dapat diisi. Variabel pertama adalah citra masukan yaitu imgarr, variabel kedua adalah [low_in high_in] dan variabel ketiga adalah [low_out high_out].

Untuk mengurangi kecerahan citra maka nilai pada low_in divariasikan, high_in dibuat bernilai satu dan variabel ketiga bernilai [0 1 [. Untuk menambah kecerahan citra maka nilai pada low_out divariasikan, high_out dibuat bernilai satu dan variabel kedua bernilai [0 1]. Gambar 3 menunjukkan perbandingan hasilhasil penerapan teknik brightness adjustment dan contrast stretching pada citra pantai.

2) Pengolahan Citra 
Setelah diperoleh citra keluaran brightness adjustment, selanjutnya dilakukan proses image processing. Image processing terdiri dari proses ekstraksi ciri warna, segmentasi, operasi morfologi, ekstraksi ciri tekstur, dan klasifikasi.

a) Ekstraksi ciri warna, bertujuan untuk mendapatkan ciri warna dari frame berupa komponen R (Red), G (Green) dan B (Blue).

b) Segmentasi citra, bertujuan untuk membagi objek yang terdapat pada frame menjadi

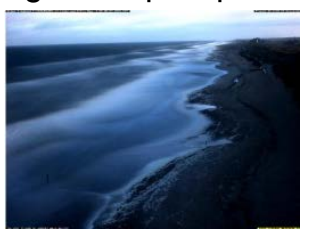

(a)

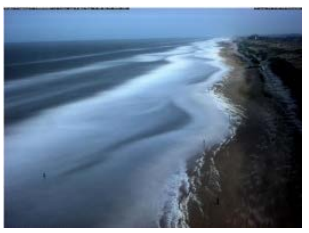

(c)

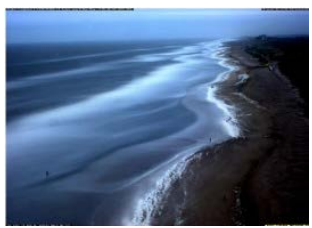

(e)
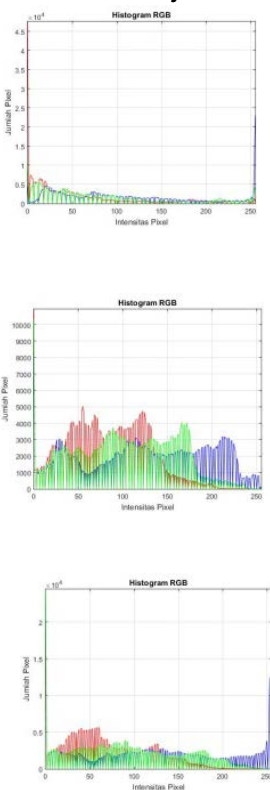

beberapa daerah terpisah dimana setiap daerah memiliki kesamaan yang mengacu pada ciri warna RGB. Segmentasi citra dilakukan dengan menggunakan algoritma Self-Organizing Map (SOM).

c) Operasi morfologi, bertujuan untuk meningkatkan keluaran segmentasi dengan cara mengurangi noise yang tidak
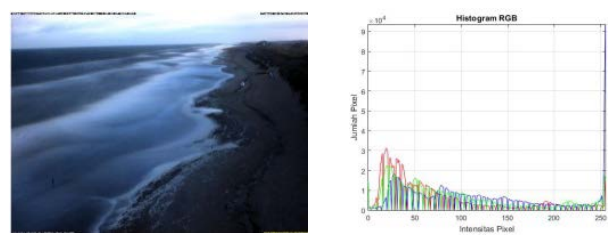

(b)
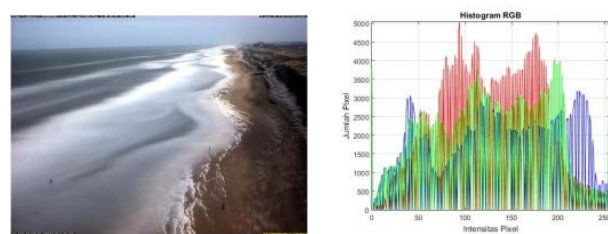

(d)
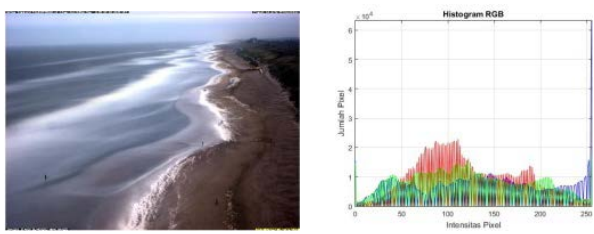

(f)

Gambar 3. Perbandingan citra hasil pra-pengolahan citra masing-masing untuk sampel citra pagi (atas), siang (tengah), sore (bawah) menggunakan teknik brightness adjustment $(\mathrm{a})(\mathrm{c})(\mathrm{e})$, dan teknik contrast stretching (b)(d)(f)

diperlukan pada objek. Operasi morfologi yang dilakukan adalah operasi transformasi citra biner, operasi opening, operasi closing, dan operasi imfill.

d) Ekstraksi ciri tekstur, bertujuan untuk mendapatkan nilai entropi, energi dan homogenitas. Ekstraksi ciri tekstur menggunakan metode GLCM (Grey Level Co-ocurrence Matrix).

e) Klasifikasi, bertujuan untuk memberi label kelas (darat, laut, dan langit) pada setiap daerah hasil segmentasi. Klasifikasi dilakukan dengan menggunakan metode $K$ Nearest Neighbor (K-NN).

\section{3) Ekstraksi Garis Pantai}

Proses ekstraksi garis pantai dilakukan dengan menggunakan pemindaian label darat pada hasil yang diperoleh setelah klasifikasi KNN. Pemindaian label dibuat terhadap piksel tetangga dari citra berlabel darat. Jika piksel tetangga bukan anggota label darat, pikselnya ditandai sebagai piksel garis pantai. Kumpulan piksel yang ditandai sebagai piksel garis pantai akan membentuk area garis pantai. Gambar 4 menunjukkan proses ekstraksi garis pantai.

\section{Hasil dan PEMBahasan}

Simulasi pengukuran kinerja deteksi garis pantai menggunakan teknik brightness adjustment adalah berdasarkan pada Gambar 2. Sebuah mekanisme perbandingan kinerja dengan teknik contrast stretching juga dilakukan untuk mendapatkan evaluasi kinerja deteksi garis pantai dengan kerangka kerja eksisting [4].

Seperti ditunjukkan pada Gambar 5, penerapan teknik brightness adjustment mampu menghasilkan kinerja deteksi garis pantai yang akurat adalah pada pengaturan ambang batas masing-masing sebesar $-20 \%$ pada sampel citra 
pagi, $-40 \%$ pada sampel citra siang, dan $-35 \%$ pada sampel citra sore. Nilai ambang brightness adjustment ini didapatkan dari pengujian terhadap 16 nilai ambang mulai dari rentang $40 \%$ hingga $+40 \%$ dengan perubahan $\pm 5 \%$ pada masing-masing citra uji. Hal ini menunjukkan bahwa perubahan kekontrasan citra pantai sangat menentukan akurasi deteksi garis pantai. Perubahan kekontrasan citra dapat terjadi sewaktu-waktu dan terus menerus bergantung pada perubahan cuaca yang berdampak pada perubahan karakteristik warna
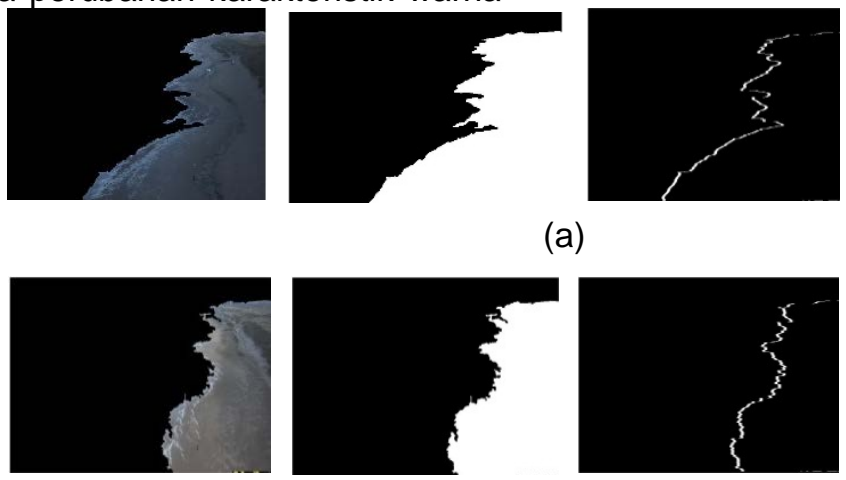

(b)
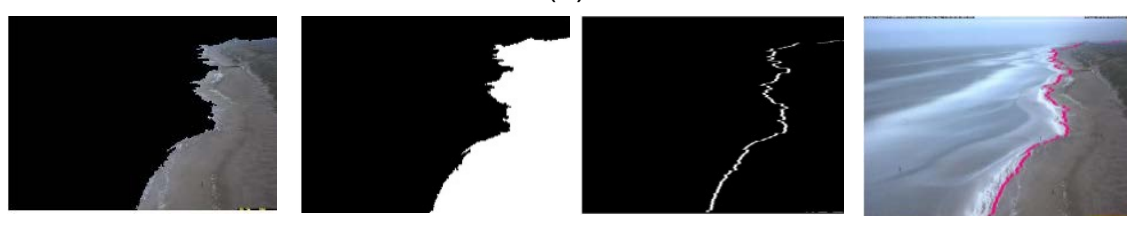

(c)

Gambar 4. Prosedur ekstraksi garis pantai berdasarkan luaran citra brightness adjustment, (a) Sampel citra pagi, (b) Sampel citra siang, (c) Sampel citra sore
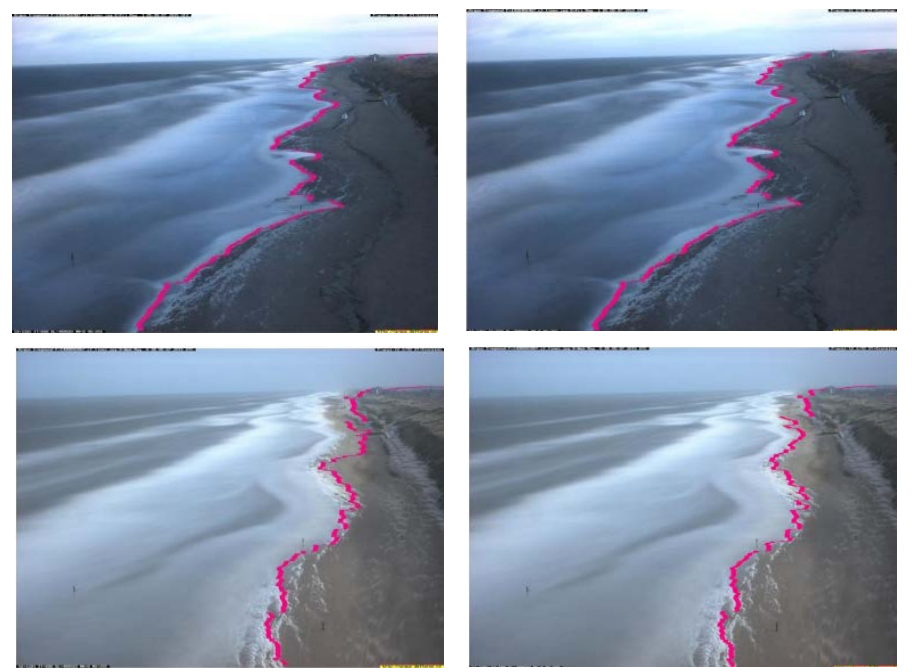


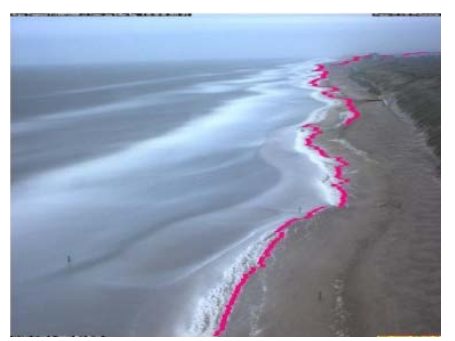

(a)

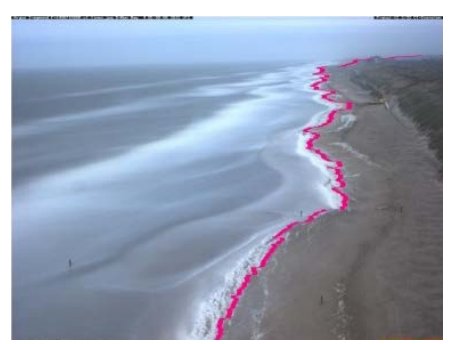

(b)

Gambar 5. Perbandingan kinerja sistem deteksi garis pantai pada sampel citra pagi (atas), siang (tengah), sore (bawah) dengan menggunakan, (a) Contrast stretching, dan (b) Brightness adjustment

a) Pada pagi hari ketika matahari akan terbit, intensitas cahaya matahari bernilai rendah (cenderung gelap). Dengan rendahnya iluminasi pada frame video monitoring pantai pagi hari, maka diperlukan brightness adjustment -20\% untuk mendapatkan deteksi garis pantai yang akurat.

b) Pada siang hari matahari bersinar terik, yang menyebabkan intensitas cahaya matahari bernilai tinggi (cenderung terang). Dengan tingginya iluminasi pada frame video monitoring pantai siang hari, maka diperlukan brightness adjustment $-40 \%$ atau dua kali lipat nilai ambang pagi hari untuk mendapatkan deteksi garis pantai yang akurat.

c) Frame video monitoring pantai sore hari memerlukan brightness adjustment -35\% untuk mendapatkan deteksi garis pantai yang akurat. Hal ini dikarenakan pada sore hari, intensitas cahaya matahari mulai mengalami penurunan dibandingkan dengan siang hari.

\section{Kesimpulan}

Hasil simulasi telah menujukan bahwa penerapan teknik brightness adjustment terbukti dapat mengatasi pengaruh iluminasi/ pencahayaan matahari berlebih pada citra video pantai sehingga didapatkan deteksi garis pantai yang akurat. Diperlukan ambang batas penyesuaian yang berbeda untuk waktu pengambilan video yang berbeda. Secara berturut-turut dari ketiga citra uji, didapatkan bahwa untuk pagi hari, siang hari dan sore hari diperlukan brightness adjustment $-20 \%,-40 \%$ dan $-35 \%$.

\section{DAFTAR PUSTAKA}

[1] Rigos, A., O.P. Andreadis, M. Andreas, M.I. Vousdoukas, G.E. Tsekouras and A. Velegrakis. Shoreline Extraction from Coastal Images Using Chebyshev Polynomials and RBF Neural Networks. Proceeding of the 10th International Conference on Artificial Intelligence Applications and Innovations. Springer, Berlin, Heidelberg. 2014: 593-603.

[2] Widyantara, I.M.O., N.M.A.E.D. Wirastuti, I.M.D.P. Asana and I.B.P. Adnyana. Image Enhancement Using Morphological Contrast Enhancement for Video Based Image Analysis. Proceeding of the International Conference on Data and Software Engineering (ICoDSE). Denpasar. 2016: 26-27.

[3] Eun Kyeong Kim, Hansoo Lee, Sungshin Kim and Hyunhak Cho. Automatic Brightness Adjustment System by Fuzzy Inference System for Object Recognition. Proceeding of the International Fuzzy System Association and International Conference on Soft Computing and Intelligent Systems (IFSA-SCIS). Otsu. 2017: 27-30.

[4] Widyantara, I.M.O., N.M.A.E.D. Wirastuti, I.M.D.P. Asana and I.B.P. Adnyana. An Automated Approach of Shoreline Detection Applied to Digital Videos Using Data Mining. Research Journal of Applied Sciences, Engineering and Technology (RJASET). 2017; 14(3): 101-111.

[5] Putra, D. Pengolahan Citra Digital. Yogyakarta: C.V. ANDI OFFSET. 2010: 120-121 